\title{
Prevalence and association of asthma and allergic sensitization with dietary factors in schoolchildren: data from the french six cities study
}

Danielle Saadeh ${ }^{1,7^{*}}$, Pascale Salameh ${ }^{1}$, Denis Caillaud ${ }^{2}$, Denis Charpin ${ }^{3}$, Frédéric De Blay ${ }^{4}$, Christine Kopferschmitt ${ }^{4}$, François Lavaud ${ }^{5}$, Isabella Annesi-Maesano ${ }^{6}$, Isabelle Baldi ${ }^{7}$ and Chantal Raherison ${ }^{7,8}$

\begin{abstract}
Background: The prevalence of asthma and allergy has recently risen among children. This increase in prevalence might be related to various factors, particularly diet. The aim of this study is to assess the prevalence and association of asthma and allergic sensitization with dietary factors in the French Six Cities Study.

Methods: Cross-sectional studies were performed among 7432 schoolchildren aged 9-11 years in Bordeaux, Clermont-Ferrand, Créteil, Marseille, Reims, and Strasbourg. Parental questionnaires, based on the International Study on Asthma and Allergies in Childhood (ISAAC), were used to collect information on allergic diseases and potential exposure factors including a food frequency questionnaire to evaluate dietary habits. Skin prick testing to common allergens for allergic sensitization and bronchial hyper-responsiveness (BHR) testing to exercise were performed. Confounders control was performed with multiple logistic regressions.

Results: Asthma symptoms, asthma and allergic sensitization were more prevalent in boys than in girls and were more prevalent in the South than in the North of France. After adjustment for confounders, fruit juice intake was associated with a low prevalence of lifetime asthma (ORa [95 \% Cl]; 0.73 [0.56-0.97]), butter intake was positively associated with atopic wheeze (1.48 [1.07-2.05]) and having lunch at the canteen 1-2 times/week compared to never or occasionally was associated with a lower prevalence of past year wheeze (0.71 [0.52-0.96]), lifetime asthma (0.76 [0.60-0.96]) and allergic sensitization (0.80 [0.67-0.95]). Meat intake was inversely related to past year wheeze among atopic children $(0.68$ [0.50-0.98]) while fast food consumption and butter intake were associated with an increase prevalence of asthma (2.39 [1.47-3.93] and 1.51 [1.17-2.00] respectively). Fish intake was associated with a lower prevalence of asthma among non-atopic children (0.61 [0.43-0.87]. None of the dietary factors was associated with BHR.

Conclusions: Diet is associated with wheeze, asthma and allergic sensitization but not with BHR in children. These results provide further evidence that adherence to a healthy diet including fruits, meat and fish seems to have a protective effect on asthma and allergy in childhood. However, prospective and experimental studies are needed to provide causal evidence concerning the effect of diet on asthma and atopy.
\end{abstract}

Keywords: Allergic sensitization, Asthma, Children, Dietary factors, French Six Cities Study, ISAAC

\footnotetext{
* Correspondence: daniellesaadeh@hotmail.com

${ }^{1}$ Clinical and Epidemiological Research Laboratory, Lebanese University, Hadath, Lebanon

'INSERM U897, Institut de Santé Publique d'Epidémiologie et de Développement, Laboratoire Santé Travail Environnement, Université de Bordeaux, Bordeaux, France

Full list of author information is available at the end of the article
}

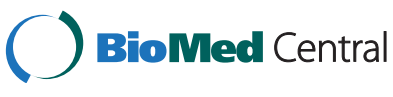

(c) 2015 Saadeh et al. Open Access This article is distributed under the terms of the Creative Commons Attribution 4.0 International License (http://creativecommons.org/licenses/by/4.0/), which permits unrestricted use, distribution, and reproduction in any medium, provided you give appropriate credit to the original author(s) and the source, provide a link to the Creative Commons license, and indicate if changes were made. The Creative Commons Public Domain Dedication waiver (http://creativecommons.org/publicdomain/zero/1.0/) applies to the data made available in this article, unless otherwise stated. 


\section{Background}

The prevalence of asthma and allergic diseases among children and adolescents has rapidly increased over the last 10 years, especially in the Western world [1-4], and it has become a serious public health issue [5]. Unfortunately, the reasons for this increase are still obscure but risk factors including genetic predisposition and environmental factors (change in lifestyle, air pollution, etc.) could be responsible [6,7]. In fact, one hypothesis to explain the occurrence of asthma and allergies in childhood, are related to lifestyle factors. Among these factors, dietary habits may be one of the contributing factors $[8,9]$.

Several studies have shown that some food could increase the risk of asthma and allergies [10-12], while others hypothesize that other food products could have a protective effect on allergies, such as vegetables [13-15], and oily fish [11]. Dietary fat intake was shown to have an association with atopy in children. Therefore, high margarine consumption was positively associated with hay fever, while butter consumption was negatively associated with hay fever [16]. Furthermore, protein-rich and fat-rich foods of animal origin were associated with a higher prevalence of asthma $[17,18]$. Special attention was given to n-3-poly unsaturated fatty acids (PUFA) intake. In fact, there is evidence that fish rich in n-3-PUFA has antiinflammatory properties and may modulate the immune response towards a Th1 type [19]. In fact, fish consumption was shown to have a protective effect on childhood asthma in several studies [20-22]. Moreover, in the ISAAC, ecological studies suggested a relationship between the intake of trans-fatty acids and the prevalence of childhood asthma and allergies [23], and a consistent inverse relationship was seen between prevalence rates of asthma, allergic rhinitis and eczema and the intake of vegetables [24]. Furthermore, decreased intake of antioxidants found mostly in fresh fruit and vegetables, has been shown to have a role in the development of atopy [19, 24, 25].

From the methodological point of view, the relationship between diet and health can be assessed at the level of food studied independently from each other. However, we hypothesize that nutrition is a general complex habit, and that the association of food products may differ from one individual to another with regard to their effect on health $[26,27]$.

In this study, we aim to assess, the prevalence and association of asthma, asthma symptoms, allergic sensitization and bronchial hyper-responsiveness (BHR) with dietary factors in a large French population-based sample of schoolchildren.

\section{Methods}

\section{Study design and study population}

The data set is part of the French Six Cities Study. Crosssectional studies were conducted, in 2000-2001, in 6
French ISAAC centers: Bordeaux, Clermont-Ferrand, Créteil, Marseille, Reims, and Strasbourg. Among a total of 9000 children aged 9-11 years old and in 4th and 5th grade, 7432 agreed to participate in the French six cities survey. We classified their place of residence according to the study centers divided into North (Créteil, Reims, and Strasbourg) and South (Bordeaux, Clermont-Ferrand and Marseille) of France. Figure 1 show the flow chart of participants with the number of children who underwent ISAAC questionnaire, physical examination, lung function measurements, BHR test and Skin Prick Tests.

\section{Questionnaire}

Standardized self-administered epidemiological questionnaires were developed on demographics, wheezing, asthma, allergic rhinitis (AR) and atopic eczema. The main questions were derived from the International Study of Asthma and Allergies in Childhood (ISAAC) questionnaire [28]. These included detailed questions on the occurrence and severity of atopic symptoms (asthma, allergic rhinitis, eczema) and their potential exposure factors. Such questions had been previously validated and translated from English into French by a native French speaker, then back-translated into English by a native English speaker. All questionnaires were completed by the parents.

\section{Dietary assessment}

Children's feeding dietary habits were collected by a food frequency questionnaire (FFQ). The FFQ included the following food items and dietary factors commonly consumed in France: soft drinks, fruit juice, cooked vegetables, raw vegetables, citrus fruit, red meat, white fish, dairy products, fast food, and canteen lunch. The FFQ was divided by frequency of consumption per week (never/occasionally, 1-2 times, $\geq 3$ times). In addition a question was added, independently from the FFQ, to assess the most consumable fatty acids by children (butter, margarine and vegetable oil).

\section{Clinical tests}

The children's consent was obtained before conducting clinical examination in their classrooms. Then a physician conducted a physical examination including data on respiratory symptoms, skin prick tests, lung function measurements and BHR testing. Furthermore, data on height and weight were obtained for 6733 children. Fieldworkers were trained to conduct these respiratory function tests and physical examinations.

\section{Skin-prick test (SPT)}

SPTs for atopy were performed on 6461 children using Stallerpoints (Stallergènes Laboratoires, Antony, France). The skin tests were performed by the SPT technique 


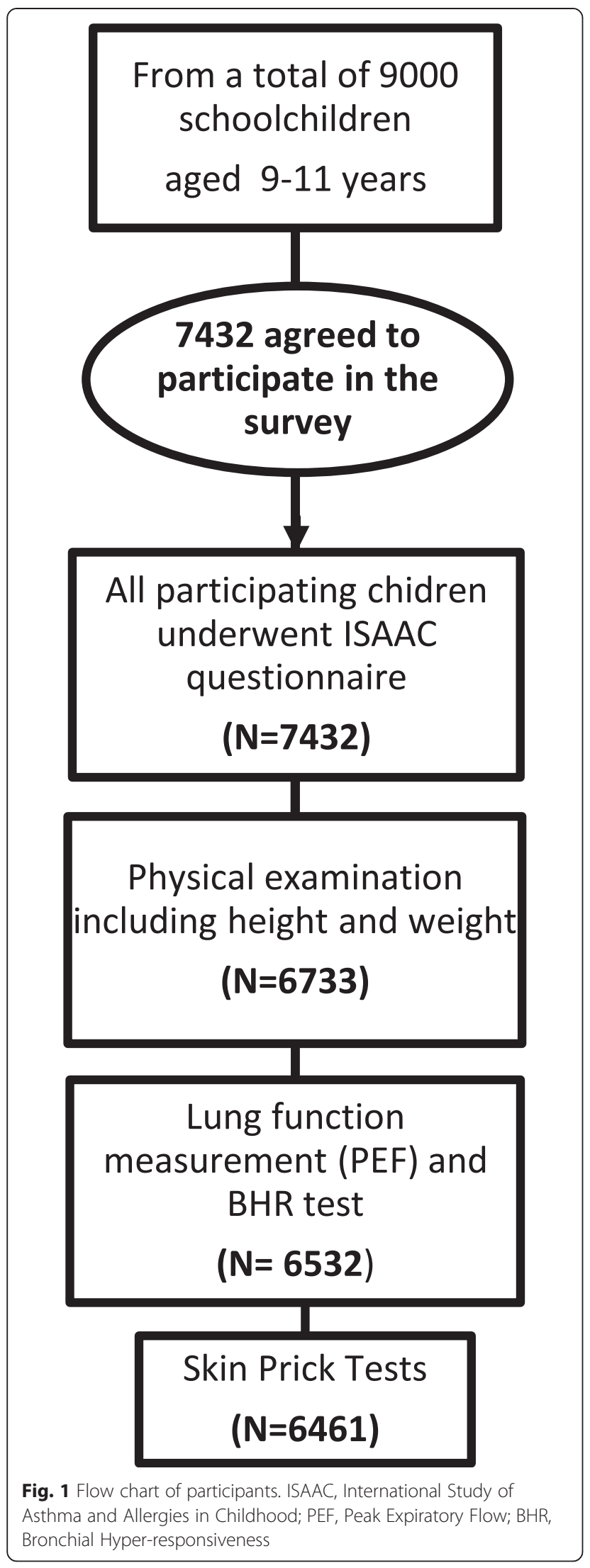

according to the ISAAC protocol [29]. Children were tested for the following common food and aeroallergens: Dermatophagoides pteronyssinus, Dermatophagoides farinaee, cat fur, Alternaria tenius, mixed grass and tree pollens, peanut, codfish, Blatta germanica and egg. At least one positive reaction (weal size at least $3 \mathrm{~mm}$ and greater than the negative control) was defined as a positive SPT, therefore having an allergic sensitization.

\section{Bronchial hyper-responsiveness (BHR) test}

BHR was assessed according to the standardized protocol of the run test [30-32]. Baseline peak expiratory flow (PEF) was measured in 6532 children who agreed. Post-exercise PEF was recorded immediately after the challenge, five minutes, ten minutes and fifteen minutes later. A child was considered to have BHR to exercise if the decrease in PEF after exercise exceeded $10 \%$. Subsequently, if a fall in PEF of $10 \%$ was determined or if the child presented any respiratory symptom, he was first examined by the physician and a $\beta 2$-agonist with inhalation chamber was administered in order to ensure the reversibility of the bronchospasm.

\section{Health outcomes}

The following health outcomes were considered in the analysis: Past year wheeze (a history of "chest wheezing or whistling in the chest over the past 12 months" (Yes/No)) used as an indicator of childhood asthma; Atopic wheeze was defined as wheeze during the past year and a positive SPT; Lifetime asthma (a history of asthma at some point in life according to the standardized question "Has your child ever had asthma?" (Yes/No)) used to investigate the lifetime prevalence of asthma; Atopy in children was defined as having an allergic sensitization as described above in the SPT paragraph; and BHR as described in the paragraph above.

\section{Statistical analysis}

All continuous variables are presented as mean $(\mathrm{m})$ and standard deviation (SD), and the categorical variables are presented as frequencies. Correlations between dietary factors and health outcomes were determined by the Pearson chi-square test.

Multiple logistic regressions models were used to assess the association between dietary factors that were statistically significant in the univariate analysis $(\mathrm{p} \leq 0.2)$ as independent variables and all investigated health outcomes as dependent variables. Hosmer and Lemeshow test was calculated for the evaluation of the model's goodness-of-fit. The relative risks of asthma related symptoms and allergic sensitization based on all dietary factors were estimated by calculating the adjusted odds ratios $(\mathrm{ORa})$ and corresponding $95 \%$ confidence intervals $(95 \% \mathrm{CI})$. ORs were adjusted for potential confounders to control for increased risk of atopy. 
The following potential confounders were considered: gender, place of residence (North or South of France according to ISAAC centers), parental atopic disease (defined by whether the father or the mother of the child had ever suffered from asthma, AR or eczema), number of siblings $(0,1-2, \geq 3)$, maternal education, parental ethnic origins, breastfeeding, day care center or nursery, overweight and obesity and current exposure to environmental tobacco smoke (ETS) ("Does anybody at present smoke inside your child's home?" Yes/No).

Differences between strata were assessed by z-test. Depending on prevalence and completeness of variables, the numbers of subjects in the models differ.

All reported probability values ( $p$-values) were based on two-sided tests and a $p<0.05$ was considered statistically significant. All analyses were performed using the Statistical Package for Social Science (SPSS) version 21.

\section{Results}

\section{Descriptive results}

The figure illustrates the flow of participants with the number of children who underwent ISAAC questionnaire, data of physical examination, SPT, the lung function measurements and BHR test. About $82 \%$ of the children aged 9-11 years (7432/9000) agreed to participate in the study. Among these children, $21 \%$ were from the Créteil ISAAC center, $18 \%$ from Bordeaux, $16 \%$ from Clermont-Ferrand, $16 \%$ from Marseille, $16 \%$ from Strasbourg and $13 \%$ from Reims. Characteristics of the children who participated in the study are shown in Table 1. About $48 \%$ of these children were breast-fed, $64 \%$ of them were breast-fed for less than four months and $36 \%$ were breast-fed for four months or more. About $30 \%$ of the children were in a day care center or nursery for at least six months in their infancy.

\section{Prevalence of asthma symptoms, asthma and allergic sensitization}

The prevalence of health outcomes assessed in this study was as follows: $3.5 \%$ for atopic wheeze; $6.7 \%$ for past year wheeze; and $8.9 \%$ for lifetime asthma. The prevalence of BHR to exercise was $7.9 \%$.

Among the 6461 children who underwent SPT, $27.5 \%$ had at least one positive test and were considered as having allergic sensitization (sensitized children); $11.3 \%$ of them were mono-sensitized (had only one positive SPT) and $16.2 \%$ were poly-sensitized (had two or more positive SPTs). The most prevalent allergen SPT positivity in decreasing order was as follows: Dermatophagoides pteronyssinus (17 \%), Dermatophagoides farinaee (11.4\%), grass pollen $(9.5 \%)$, mixed tree $(3.8 \%)$, cat fur (3.9\%) and Alternaria tenius (2.8 \%).

After adjustment for confounders in logistic regression models, boys were significantly more affected than girls by
Table 1 Characteristics of the children who underwent clinical examination and their parents who completed the questionnaire $(n=7432)$

\begin{tabular}{|c|c|c|c|}
\hline Characteristics & Child & Mother & Father \\
\hline Age, years $(m \pm S D)$ & & $38.4 \pm 5.1$ & $41.4 \pm 6.3$ \\
\hline 9 years (\%) & 27.8 & & \\
\hline 10 years (\%) & 48.7 & & \\
\hline 11 years (\%) & 23.5 & & \\
\hline Gender (male, \%) & 49.4 & & \\
\hline \multicolumn{4}{|l|}{ Place of residence (\%) } \\
\hline North of France & 49.9 & & \\
\hline South of France & 50.1 & & \\
\hline Weight in $\mathrm{Kg}(\mathrm{m} \pm \mathrm{SD})$ & $36.1 \pm 8.3$ & & \\
\hline Height in meter $(m \pm S D)$ & $1.4 \pm 0.1$ & & \\
\hline Overweight and obesity (\%) & 21.0 & & \\
\hline Current ETS (\%) & 40.0 & & \\
\hline Parental atopic disease (\%) & 39.5 & & \\
\hline \multicolumn{4}{|l|}{ Ethnic origins $(\%)^{a}$} \\
\hline Metropolitan France & & 66.4 & 60.8 \\
\hline French overseas departments & & 3.2 & 2.1 \\
\hline Southern Europe & & 3.5 & 3.6 \\
\hline Northern Africa & & 7.6 & 8.3 \\
\hline Sub-Saharan Africa & & 2.5 & 2.6 \\
\hline Asia & & 3.1 & 3.1 \\
\hline Other & & 3.0 & 2.9 \\
\hline \multicolumn{4}{|l|}{ Education (\%) ${ }^{a}$} \\
\hline Primary & & 9.8 & 9.4 \\
\hline Secondary & & 37.5 & 32.3 \\
\hline High school and university & & 31.7 & 30.1 \\
\hline Other & & 4.3 & 4.2 \\
\hline \multicolumn{4}{|l|}{ Number of siblings (\%) } \\
\hline No siblings & 47.9 & & \\
\hline 1-2 siblings & 46.1 & & \\
\hline$\geq 3$ siblings & 6.0 & & \\
\hline
\end{tabular}

ETS Exposure to Tobacco Smoke

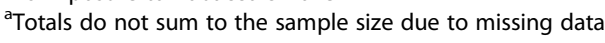

atopic wheeze (ORa 0.58, $95 \%$ CI [0.42-0.80]), past year wheeze (ORa 0.74, 95 \% CI [0.57-0.96]) lifetime asthma (ORa 0.56, $95 \%$ CI [0.45-0.69]) and allergic sensitization (ORa 0.68, $95 \%$ CI [0.59-0.79]), but not with BHR. We also found significant differences between Northern and Southern cities of France and prevalence of asthma symptoms, allergic sensitization and BHR. Therefore, atopic wheeze, allergic sensitization and BHR were more prevalent in the South than in the North (ORa 1.46, 95 \% CI [1.05-2.04]; ORa 1.53, $95 \%$ CI [1.32-1.78] and ORa 1.53, 95 \% CI [1.20-1.94] respectively). 
Table 2 Consumption frequency of the dietary factors included in the FFQ $(n=7432)$

\begin{tabular}{|c|c|c|}
\hline Dietary factors & Number & Percent \\
\hline \multicolumn{3}{|l|}{ Soft drinks intake } \\
\hline Never/occasionally & 3781 & 50.9 \\
\hline 1-2 times/week & 1909 & 25.7 \\
\hline$\geq 3$ times/week & 1742 & 23.4 \\
\hline \multicolumn{3}{|l|}{ Fruit juice intake } \\
\hline Never/occasionally & 2654 & 35.7 \\
\hline 1-2 times/week & 1515 & 20.4 \\
\hline$\geq 3$ times/week & 3263 & 43.9 \\
\hline \multicolumn{3}{|c|}{ Cooked vegetables intake } \\
\hline Never/occasionally & 1451 & 19.5 \\
\hline 1-2 times/week & 1639 & 22.1 \\
\hline$\geq 3$ times/week & 4342 & 58.4 \\
\hline \multicolumn{3}{|l|}{ Raw vegetables intake } \\
\hline Never/occasionally & 2258 & 30.4 \\
\hline 1-2 times/week & 2062 & 27.7 \\
\hline$\geq 3$ times/week & 3112 & 41.9 \\
\hline \multicolumn{3}{|l|}{ Citrus fruit intake } \\
\hline Never/occasionally & 3087 & 41.5 \\
\hline 1-2 times/week & 2095 & 28.2 \\
\hline$\geq 3$ times/week & 2250 & 30.3 \\
\hline \multicolumn{3}{|l|}{ Red meat intake } \\
\hline Never/occasionally & 1738 & 23.4 \\
\hline 1-2 times/week & 2796 & 37.6 \\
\hline$\geq 3$ times/week & 2898 & 39.9 \\
\hline \multicolumn{3}{|l|}{ Fish intake } \\
\hline Never/occasionally & 5695 & 76.6 \\
\hline 1-2 times/week & 1453 & 19.6 \\
\hline$\geq 3$ times/week & 284 & 3.8 \\
\hline \multicolumn{3}{|l|}{ Dairy products intake } \\
\hline Never/occasionally & 1085 & 14.6 \\
\hline 1-2 times/week & 323 & 4.3 \\
\hline$\geq 3$ times/week & 6024 & 81.1 \\
\hline \multicolumn{3}{|c|}{ Fast food consumption $(N=6515)$} \\
\hline Never/occasionally & 6065 & 93.1 \\
\hline 1-2 times/week & 413 & 6.3 \\
\hline$\geq 3$ times/week & 37 & 0.6 \\
\hline \multicolumn{3}{|c|}{ Canteen lunch $(N=6790)$} \\
\hline Never/occasionally & 2211 & 32.6 \\
\hline 1-2 times/week & 1443 & 21.3 \\
\hline$\geq 3$ times/week & 3136 & 46.2 \\
\hline
\end{tabular}

\section{Dietary factors and allergic diseases}

Frequencies of consumption of the dietary factors included in the FFQ are shown in Table 2. Concerning fatty acids intake, $29 \%$ of children consumed butter, $64 \%$ vegetable oil and $28 \%$ margarine. The majority of school children (93\%) never or occasionally consumed fast food. In addition, about $46 \%$ of the children always ate their lunch at the canteen, $21 \%$ ate from time to time at the canteen and $33 \%$ never ate at the canteen.

Our results showed that butter intake was associated positively with past year wheeze (ORa 1.24, $95 \%$ CI [1.01-1.54]) and lifetime asthma (ORa 1.24, $95 \%$ CI [1.04-1.49]) while consumption of vegetable oil was positively associated with atopic wheeze (ORa 1.56, $95 \%$ CI [1.16-2.11]).

Table 3 shows the associations between dietary factors and atopic wheeze, past year wheeze, lifetime asthma, SPT positivity and BHR. Atopic wheeze was negatively associated with fruit juice consumption equal or more than 3 times per week compared to none or occasional consumption (ORa 0.66, 95 \% CI [0.43-0.91]; $p=0.007$ ) and compared to none or occasional eating at the canteen, canteen lunch 1 to 2 times per week was as well negatively associated with atopic wheeze (ORa 0.57, $95 \%$ CI [0.37-0.88]). Furthermore, consumption of red meat 1-2 times/week vs. never or occasionally was found to be positively associated with atopic wheeze (ORa 1.35, 95 \% CI [1.05-1.68]; $p=0.022$ ). Consumption of white fish 1-2 times/week vs. never or occasionally was negatively correlated with past year wheeze (ORa 0.75, $95 \%$ CI [0.53-0.93]; $p=0.028$ ), while we found no significant associations between fish intake and SPT positivity and BHR. In addition, we found that compared to none or occasional consumption, fruit juice intake $\geq 3$ times per week was protective for lifetime asthma (ORa 0.73, 95 \% CI [0.55-0.96]). Canteen lunch 1-2 times/week vs. never or occasionally was negatively associated with past year wheeze (ORa 0.72, $95 \%$ CI [0.52-0.99]; $p=0.014$ ) and SPT positivity (ORa 0.83, $95 \%$ CI [0.69-0.99]; $p=0.001)$. Cooked vegetable intake $\geq 3$ times per week vs. never or occasionally and canteen lunch 1-2 times/week vs. never or occasionally were negatively associated with BHR (ORa 0.77, $95 \%$ CI [0.57-0.94]; $p=$ 0.009 and ORa 0.82, $95 \%$ CI [0.71-0.91]; $p=0.005$ respectively).

After adjustment for the following confounders: gender, place of residence, number of siblings, parental ethnic origins, maternal education, parental atopic disease, breastfeeding, day care center or nursery, overweight and obesity and current exposition to Environmental Tobacco Smoke (ETS), in the logistic regression models, fruit juice intake $\geq 3$ times per week compared with none or occasional consumption was still found to be protective for lifetime asthma (ORa 0.73, 95 \% CI [0.56-0.97]). In contrast, butter intake was positively associated with atopic wheeze (ORa 1.48, 95 \% CI [1.07-2.05]). Moreover, canteen lunch 1 to 2 times per week compared to never or occasionally was negatively associated with atopic wheeze 
Table 3 Association between dietary factors and atopic wheeze, past year wheeze, lifetime asthma, SPT positivity and BHR

\begin{tabular}{|c|c|c|c|c|c|c|c|c|c|c|}
\hline & \multicolumn{2}{|c|}{ Atopic wheeze ${ }^{a}$} & \multicolumn{2}{|c|}{ Past year wheeze ${ }^{a}$} & \multicolumn{2}{|c|}{ Lifetime asthma $^{a}$} & \multicolumn{2}{|c|}{ SPT positivity ${ }^{a}$} & \multicolumn{2}{|l|}{$\mathrm{BHR}^{\mathrm{a}}$} \\
\hline & $\overline{\mathrm{OR}}$ & $95 \% \mathrm{Cl}$ & $\overline{\mathrm{OR}}$ & $95 \% \mathrm{Cl}$ & $\overline{\mathrm{OR}}$ & $95 \% \mathrm{Cl}$ & $\overline{\mathrm{OR}}$ & $95 \% \mathrm{Cl}$ & $\overline{\mathrm{OR}}$ & $95 \% \mathrm{Cl}$ \\
\hline Soft drink intake $(N)$ & 5200 & & 2322 & & 6089 & & 5902 & & 5954 & \\
\hline Never/occasionally & 1 & Ref & 1 & Ref & 1 & Ref & 1 & Ref & 1 & Ref \\
\hline 1-2 times/week & 1.05 & 0.70 to 1.58 & 1.00 & 0.72 to 1.38 & 1.07 & 0.82 to 1.40 & 1.18 & 0.98 to 1.43 & 1.10 & 0.82 to 1.47 \\
\hline$\geq 3$ times/week & 0.89 & 0.57 to 1.39 & 0.88 & 0.62 to 1.26 & 1.03 & 0.77 to 1.37 & 0.99 & 0.81 to 1.22 & 0.94 & 0.68 to 1.30 \\
\hline$p$-value & & 0.839 & & 0.562 & & 0.615 & & 0.062 & & 0.192 \\
\hline Fruit juice intake $(N)$ & 5200 & & 2322 & & 6089 & & 5902 & & 5954 & \\
\hline Never/occasionally & 1 & Ref & 1 & Ref & 1 & Ref & 1 & Ref & 1 & Ref \\
\hline 1-2 times/week & 0.76 & 0.53 to 1.09 & 0.97 & 0.72 to 1.30 & 1.02 & 0.81 to 1.29 & 0.94 & 0.79 to 1.11 & 1.01 & 0.77 to 1.31 \\
\hline$\geq 3$ times/week & 0.66 & 0.43 to 0.91 & 0.89 & 0.64 to 1.24 & 0.73 & 0.55 to 0.96 & 0.96 & 0.79 to 1.15 & 1.15 & 0.87 to 1.53 \\
\hline$p$-value & & 0.007 & & 0.275 & & 0.054 & & 0.492 & & 0.793 \\
\hline Cooked vegetable intake $(M)$ & 5200 & & 2322 & & 6089 & & 5902 & & 5954 & \\
\hline Never/occasionally & 1 & Ref & 1 & Ref & 1 & Ref & 1 & Ref & 1 & Ref \\
\hline 1-2 times/week & 0.99 & 0.55 to 1.79 & 1.19 & 0.76 to 1.87 & 1.02 & 0.70 to 1.49 & 0.88 & 0.66 to 1.16 & 1.06 & 0.71 to 1.59 \\
\hline$\geq 3$ times/week & 0.98 & 0.66 to 1.45 & 0.94 & 0.68 to 1.29 & 1.10 & 0.86 to 1.40 & 1.05 & 0.88 to 1.26 & 0.77 & 0.57 to 0.94 \\
\hline$p$-value & & 0.078 & & 0.170 & & 0.102 & & 0.775 & & 0.009 \\
\hline Raw vegetable intake $(N)$ & 5200 & & 2322 & & 6089 & & 5902 & & 5954 & \\
\hline Never/occasionally & 1 & Ref & 1 & Ref & 1 & Ref & 1 & Ref & 1 & Ref \\
\hline 1-2 times/week & 1.05 & 0.68 to 1.63 & 0.98 & 0.69 to 1.40 & 0.94 & 0.70 to 1.25 & 0.99 & 0.81 to 1.21 & 1.05 & 0.76 to 1.44 \\
\hline$\geq 3$ times/week & 1.07 & 0.75 to 1.54 & 1.05 & 0.78 to 1.41 & 1.11 & 0.87 to 1.40 & 1.03 & 0.87 to 1.22 & 1.15 & 0.88 to 1.48 \\
\hline$p$-value & & 0.094 & & 0.682 & & 0.532 & & 0.428 & & 0.645 \\
\hline Fruit intake $(N)$ & 5200 & & 2322 & & 6089 & & 5902 & & 5954 & \\
\hline Never/occasionally & 1 & Ref & 1 & Ref & 1 & Ref & 1 & Ref & 1 & Ref \\
\hline 1-2 times/week & 1.06 & 0.72 to 1.56 & 1.15 & 0.84 to 1.58 & 1.10 & 0.85 to 1.41 & 0.98 & 0.82 to 1.17 & 1.20 & 0.90 to 1.59 \\
\hline$\geq 3$ times/week & 1.06 & 0.71 to 1.57 & 1.17 & 0.85 to 1.62 & 0.99 & 0.77 to 1.29 & 1.11 & 0.93 to 1.33 & 1.31 & 0.99 to 1.74 \\
\hline$p$-value & & 0.109 & & 0.670 & & 0.351 & & 0.592 & & 0.468 \\
\hline Red meat intake $(\mathrm{N})$ & 5200 & & 2322 & & 6089 & & 5902 & & 5954 & \\
\hline Never/occasionally & 1 & Ref & 1 & Ref & 1 & Ref & 1 & Ref & 1 & Ref \\
\hline 1-2 times/week & 1.35 & 1.05 to 1.68 & 1.03 & 0.69 to 1.52 & 0.84 & 0.60 to 1.18 & 0.94 & 0.74 to 1.19 & 1.26 & 0.89 to 1.80 \\
\hline$\geq 3$ times/week & 0.83 & 0.59 to 1.16 & 0,89 & 0.68 to 1.18 & 0.93 & 0.75 to 1.16 & 0.96 & 0.83 to 1.12 & 1.25 & 0.98 to 1.59 \\
\hline$p$-value & & 0.022 & & 0.587 & & 0.261 & & 0.546 & & 0.074 \\
\hline Fish intake $(N)$ & 5200 & & 2322 & & 6089 & & 5902 & & 5954 & \\
\hline Never/occasionally & 1 & Ref & 1 & Ref & 1 & Ref & 1 & Ref & 1 & Ref \\
\hline 1-2 times/week & 2.78 & 0.66 to 11.61 & 0.75 & 0.53 to 0.93 & 1.11 & 0.61 to 2.03 & 1.05 & 0.69 to 1.61 & 1.44 & 0.69 to 3.02 \\
\hline$\geq 3$ times/week & 2.46 & 0.57 to 10.51 & 1.25 & 0.54 to 2.89 & 1.22 & 0.65 to 2.26 & 1.03 & 0.66 to 1.60 & 1.67 & 0.78 to 3.57 \\
\hline$p$-value & & 0.042 & & 0.028 & & 0.789 & & 0.882 & & 0.524 \\
\hline Dairy product intake $(N)$ & 5200 & & 2322 & & 6089 & & 5902 & & 5954 & \\
\hline Never/occasionally & 1 & Ref & 1 & Ref & 1 & Ref & 1 & Ref & 1 & Ref \\
\hline 1-2 times/week & 0.66 & 0.23 to 1.84 & 0.79 & 0.40 to 1.56 & 1.06 & 0.62 to 1.82 & 1.03 & 0.70 to 1.51 & 0.64 & 0.32 to 1.28 \\
\hline$\geq 3$ times/week & 0.70 & 0.28 to 1.78 & 0.72 & 0.37 to 1.38 & 0.99 & 0.58 to 1.69 & 0.70 & 0.46 to 1.05 & 0.97 & 0.54 to 1.74 \\
\hline$p$-value & & $<0.001$ & & 0.186 & & 0.985 & & 0.428 & & 0.271 \\
\hline Fast food consumption $(N)$ & 4635 & & 2198 & & 5809 & & 5165 & & 5211 & \\
\hline Never/occasionally & 1 & Ref & 1 & Ref & 1 & Ref & 1 & Ref & 1 & Ref \\
\hline 1-2 times/week & 0.36 & 0.07 to 1.86 & 1.68 & 0.17 to 15.92 & 1.27 & 0.15 to 10.21 & 3.46 & 0.43 to 27.52 & 0.85 & 0.10 to 6.82 \\
\hline
\end{tabular}


Table 3 Association between dietary factors and atopic wheeze, past year wheeze, lifetime asthma, SPT positivity and BHR (Continued)

\begin{tabular}{|c|c|c|c|c|c|c|c|c|c|c|}
\hline$\geq 3$ times/week & 0.53 & 0.09 to 2.95 & 1.96 & 0.19 to 19.38 & 1.47 & 0.17 to 12.18 & 2.89 & 0.35 to 23.52 & 0.92 & 0.11 to 7.75 \\
\hline$p$-value & & 0.715 & & 0.643 & & 0.302 & & 0.407 & & 0.079 \\
\hline Canteen lunch $(\mathrm{N})$ & 4817 & & 2300 & & 6046 & & 5371 & & 5414 & \\
\hline Never/occasionally & 1 & Ref & 1 & Ref & 1 & Ref & 1 & Ref & 1 & Ref \\
\hline 1-2 times/week & 0.57 & 0.37 to 0.88 & 0.72 & 0.52 to 0.99 & 0.80 & 0.62 to 1.03 & 0.83 & 0.69 to 0.99 & 0.82 & 0.71 to 0.91 \\
\hline$\geq 3$ times/week & 0.93 & 0.64 to 1.37 & 0.88 & 0.63 to 1.22 & 0.78 & 0.60 to 1.03 & 0.88 & 0.73 to 1.06 & 1.07 & 0.81 to 1.42 \\
\hline$p$-value & & $<0.001$ & & 0.014 & & 0.011 & & $<0.001$ & & 0.005 \\
\hline
\end{tabular}

SPT Skin Prick Test, BHR Bronchial hyper-responsiveness

${ }^{a}$ Adjusted for gender, place of residence, parental atopic disease, number of siblings $(0,1-2, \geq 3)$, maternal education, parental ethnic origins, breastfeeding, day care center or nursery, overweight and obesity and current exposure to environmental tobacco smoke (ETS)

(ORa 0.56, $95 \%$ CI [0.36-0.85]), past year wheeze (ORa 0.71, $95 \%$ CI [0.52-0.96]), lifetime asthma (ORa 0.76, $95 \% \mathrm{CI}[0.60-0.96])$ and allergic sensitization (ORa $0.80,95 \%$ CI [0.67-0.95]). None of the dietary factors included in the logistic regression was associated with BHR.

Analyses performed after stratification by SPT positivity are shown in Table 4. Meat intake was inversely related to past year wheeze among atopic children (ORa 0.68, $95 \%$ CI [0.50-0.98]). In contrast, fast food consumption, butter intake and canteen lunch were positively associated with wheeze during the past year among children with a positive SPT (ORa 2.39, 95 \% CI [1.47-3.93]; ORa 1.51, $95 \%$ CI [1.17-2.00] and ORa 1.64, 95 \% CI [1.20-2.30] respectively). Therefore, among children with a negative SPT, fish intake was associated significantly with fewer wheezers (ORa 0.61, 95 \% CI [0.43-0.87]).

\section{Discussion}

This study is the first in France to assess the prevalence of asthma related symptoms and allergic sensitization and their associations with dietary factors in a large populationbased sample of schoolchildren. We observed an inverse association between the consumption of fruit juice, meat and fish and the prevalence of asthma symptoms among children aged 9-11 years. In contrast, fast food consumption and butter intake were associated with an increase prevalence of asthma symptoms among atopic children.

In line with our results, a high intake of fruit juices has been shown to be protective on lung function in subjects aged 11-19 years [33]. Fruits contain antioxidants which are known to play a role on preventing asthma [25], particularly citrus fruits which are rich in vitamin $C$ [25,33]. In addition, this protective effect of fruit on asthma is also in agreement with other studies done on children [24, 34]. No significant association was found between fruit consumption and BHR, but protective effect has been previously reported [33, 35, 36].

Findings from recent studies suggest that a high intake in omega-3 fatty acids, which are mostly found in fish protects against the development of asthma and atopy in children [26, 37]. Fish is rich in $\mathrm{n}-3$ polyunsaturated fatty acids (PUFA), which are known to have antiinflammatory effects. Our results are consistent with previous studies that evaluated the association between omega-3 fatty acids and fish intake and asthma related symptoms in children [11, 20,22, 26]. The protective effect of fish consumption on asthma symptoms is as well in agreement with a report on children in phase II of the ISAAC study [21]. Our observations of no significant association between fish intake and SPT positivity and BHR are consistent with a prospective study done among children aged 5 years [38]. In contrast, the positive association of butter intake with asthma and wheezing is consistent with a study done by Farchi and colleagues in Italy [34]. In our study, the prevalence of asthma symptoms and childhood asthma was also consistent with previous studies [39].

Fast food associated with a higher prevalence of asthma among atopic children is in line with previous research that found that dietary intake of trans-fatty acids which are found in fast food, are positively associated with asthma and atopy [23, 40]. Moreover, canteen lunch, which is commonly known as being a healthy diet for schoolchildren, was negatively associated with asthma symptoms and allergic sensitization, but after stratification by SPT positivity status, positive association was shown between canteen lunch and wheezing among atopic children. Same positive association was found between meat intake and asthma among children with SPT positive. These inverse associations between meat intake, canteen lunch and asthma among children with SPT positive could be explained by the difference of food consumption between atopic and non-atopic children which can differ significantly between them. In addition, meat consumption and eating at the canteen may also vary depending on environmental, economic and social factors which can also explain the fact that we did not had a "dose effect" in our results concerning the protective effect of canteen lunch. Furthermore, we have 
Table 4 Association between dietary factors ${ }^{b}$ and past year wheeze according to skin prick test (SPT)

\begin{tabular}{|c|c|c|c|c|c|}
\hline & Whe & PT positive ${ }^{a}$ & Whe & T negative ${ }^{a}$ & Difference between \\
\hline & $\mathrm{OR}$ & $95 \% \mathrm{Cl}$ & $\mathrm{OR}$ & $95 \% \mathrm{Cl}$ & \\
\hline Soft drink intake $(N)$ & 86 & & 56 & & \\
\hline No & 1 & Ref & 1 & Ref & \\
\hline Yes & 1.03 & 0.78 to 1.33 & 1.24 & 0.91 to 1.67 & 0.832 \\
\hline Fruit juice intake $(N)$ & 123 & & 67 & & \\
\hline No & 1 & Ref & 1 & Ref & \\
\hline Yes & 1.27 & 0.94 to 1.76 & 0.96 & 0.71 to 1.32 & 0.681 \\
\hline Cooked vegetable intake $(N)$ & 157 & & 86 & & \\
\hline No & 1 & Ref & 1 & Ref & \\
\hline Yes & 0.83 & 0.51 to 1.33 & 0.95 & 0.62 to 1.40 & 0.889 \\
\hline Raw vegetable intake $(N)$ & 139 & & 77 & & \\
\hline No & 1 & Ref & 1 & Ref & \\
\hline Yes & 1.15 & 0.84 to 1.63 & 1.02 & 0.72 to 1.49 & 0.793 \\
\hline Fruit intake $(N)$ & 110 & & 57 & & \\
\hline No & 1 & Ref & 1 & Ref & \\
\hline Yes & 1.08 & 0.82 to 1.41 & 0.89 & 0.67 to 1.18 & 0.980 \\
\hline Red meat intake $(N)$ & 145 & & 83 & & \\
\hline No & 1 & Ref & 1 & Ref & \\
\hline Yes & 0.68 & 0.50 to 0.98 & 1.07 & 0.76 to 1.55 & 0.459 \\
\hline Fish intake $(N)$ & 41 & & 19 & & \\
\hline No & 1 & Ref & 1 & Ref & \\
\hline Yes & 0.77 & 0.58 to 1.02 & 0.61 & 0.43 to 0.87 & 0.040 \\
\hline Dairy product intake $(M)$ & 166 & & 91 & & \\
\hline No & 1 & Ref & 1 & Ref & \\
\hline Yes & 1.31 & 0.62 to 5.32 & 1.28 & 0.76 to 2.41 & 0.366 \\
\hline Fast food consumption $(N)$ & 17 & & 5 & & \\
\hline No & 1 & Ref & 1 & Ref & \\
\hline Yes & 2.39 & 1.47 to 3.93 & 0.66 & 0.33 to 1.09 & 0.407 \\
\hline Canteen lunch $(N)$ & 65 & & 138 & & \\
\hline No & 1 & Ref & 1 & Ref & \\
\hline Yes & 1.64 & 1.20 to 2.30 & 1.01 & 0.78 to 1.33 & 0.023 \\
\hline Butter intake $(N)$ & 65 & & 37 & & \\
\hline No & 1 & Ref & 1 & Ref & \\
\hline Yes & 1.51 & 1.17 to 2.00 & 1.18 & 0.87 to 1.54 & 0.045 \\
\hline Vegetable oil intake $(M)$ & 127 & & 69 & & \\
\hline No & 1 & Ref & 1 & Ref & \\
\hline Yes & 1.22 & 0.90 to 1.69 & 1.11 & 0.80 to 1.64 & 0.303 \\
\hline Margarine intake $(N)$ & 44 & & 22 & & \\
\hline No & 1 & Ref & 1 & Ref & \\
\hline Yes & 0.67 & 0.51 to 0.84 & 0.69 & 0.49 to 0.95 & 0.041 \\
\hline
\end{tabular}

${ }^{a}$ Adjusted for gender, place of residence, parental atopic disease, number of siblings $(0,1-2, \geq 3)$, maternal education, parental ethnic origins, breastfeeding, day care center or nursery, overweight and obesity and current exposure to environmental tobacco smoke (ETS)

${ }^{b}$ Dietary variables in the 'never' and 'less than once per week' categories were classified as NO and dietary variables in the '1-2 times per week', '3-6 times per week' and 'once per day or more often' were classified as YES 
to consider that not all children eat the same lunches at the canteen which are consisted from different menus containing different food items every day which the child could choose one according to his/her taste.

The strengths of the current study include the large number of participants, its multicenter design and the detailed health outcome assessment including information on atopic sensitization determined by SPT performed in a large number of children aged 9-11 years. Furthermore, the use of the FFQ filled by the children's parents includes detailed reliable information on the frequency of consumption of food items and beverages because parents are very likely the people the most aware of their children's diet. Concerning the evaluation of respiratory manifestations, we used internationally validated indicators [28, 41, 42].

The cross-sectional design is a major limitation of the study and it shares the same bias that we found in all observational studies, like a recall bias and not being able to demonstrate causal relationships that could have affected our results. Therefore, these retrospective results need to be confirmed by future prospective studies and/or intervention trials.

The use of the FFQ in this study to assess diet and allergic diseases may be a source of information bias. Information was obtained from children's parents who could be subject to a recall bias. However, the validity of the FFQ has been proven to be relatively good [43, 44]. Furthermore, the FFQ used in this study do not contain all food items consumed by children, mainly fatty acids consumption, that's why we analyzed their association to allergic status in a question aside. Also, this FFQ was used in several ISAAC studies but it is not been validated yet in French children aged 9-11 years. Future work will concentrate on the validation of the FFQ in this population. Moreover, we may not have taken all potential confounding variables into consideration, especially physical activity status in children due to the lack of information about it in our data set. However, the multivariate analysis decreases the probability of confounding and an effort was made to correct for gender, current exposure to environmental tobacco smoking (ETS), maternal education, breastfeeding, day care center or nursery, place of residence, number of siblings, overweight and obesity, parental ethnic origins, and parental atopic disease, which are potential confounders [45-48].

An underestimation of prevalence might also affect our results. Asthma and wheezing were reported subjectively by parents as well the identification of tobacco use and smoking. However, the internationally validated indicators we used to evaluate respiratory symptoms decrease the risk of having a differential bias [28, 41, 42].

\section{Conclusions}

In conclusion, dietary factors could be associated with asthma related symptoms and allergic sensitization in children. This study provides further evidence that adherence to a healthy diet that is rich especially in fruits, fish and meat may provide protection against allergies and especially asthma in children. Future prospective and experimental studies are needed to confirm these results so recommendations could be made to children in schools and to their parents, about the importance of adopting a healthy diet to prevent asthma and allergic diseases and about the potential health risks of adopting an unhealthy diet, considering the high prevalence of fast food consumption in children nowadays.

\section{Abbreviations}

ISAAC: International Study of Asthma and Allergies in Childhood; PUFA: Poly unsaturated fatty acids; CNIL: National Commission of Informatics and Civil Liberties; FFQ: Food frequency questionnaire; PEF: Peak expiratory flow; SPT: Skin-prick test; BHR: Bronchial hyper-responsiveness; ETS: Environmental tobacco smoke; m: Mean; SD: Standard deviation; OR: Odds ratio; aOR: Adjusted odds ratio; Cl: Confidence interval; SPSS: Statistical Package for Social Sciences.

\section{Competing interests}

The authors declare they have no competing interests.

\section{Authors' contribution}

Each of the following authors conceived and organized the study performed in their city, and participated in its design and coordination and helped to draft the manuscript: DCa in Clermont-Ferrand; DCh in Marseille; FDB and CK in Strasbourg; FL in Reims; IAM in Créteil; and CR in Bordeaux. Furthermore, DS performed statistical analysis and wrote the paper. PS and IB helped with the statistical analysis and to draft the manuscript. DS, CR, and PS have primary responsibility for final content. All authors read and approved the final manuscript.

\section{Authors' information}

Not applicable.

\section{Ethics approval}

Authorization by the "National Commission of Informatics and Civil Liberties (CNIL)" was obtained before conducting the survey. The parents of the children were informed by mail of the purposes and modalities of the survey, and their informed consent was obtained.

\section{Acknowledgements}

The authors are particularly indebted to the children, the parents, the teachers and the principals of the schools, without whom this study would have been impossible.

We wish to thank the Education Nationale, the schools doctors in the six cities and Ginette Debotte who participated in data collection. We thank Prof. Gabrielle Pauli from the Hôpital Lyautet in Strasbourg, Prof. Manuel Tunon de Lara from the Hôpital du Haut-Lévêque in Bordeaux, who contributed to conception and design of the study. We are grateful to Prof. Robert Mercier from the French Comité National contre les Maladies Respiratoires et la Tuberculose, on the aegis of which the survey was conducted.

The French Six Cities study was supported by the National Institute for Health and Medical Research (INSERM) (Programme Déterminants de la Santé), the Ministry of Health (DGS), the Environmental Programme PRIMEQUAL-PREDIT of the Ministry of Environment, the Agency for Environment and Energy Management (ADEME), the French Agency for Environmental and Occupational Health Safety (AFSSET), the mutual insurance company of the state education system [the Mutuelle Générale de l'Education Nationale (MGEN)] and the French At Home Respiratory Support Association [the Association Nationale pour le Traitement A Domicile de l'Insuffisance Respiratoire chronique (ANTADIR)]. Allergen extracts were kindly provided by Stallergènes Laboratoires (France).

This work was reported in part as an oral presentation at the annual conference of the European Respiratory Society, Spain, Barcelona, September, 2013. 


\section{Author details}

${ }^{1}$ Clinical and Epidemiological Research Laboratory, Lebanese University, Hadath, Lebanon. ${ }^{2}$ Hôpital Gabriel Montpied, Clermont-Ferrand, France. ${ }^{3}$ Hôpital Nord, Marseille, France. ${ }^{4}$ Hôpital Civil, Strasbourg, France. ${ }^{5}$ Hôpital Maison Blanche, Reims, France. ${ }^{6}$ EPAR, UMR-S 1136, Institute Pierre Louis of Epidemiology and Public Health, INSERM and UPMC Sorbonne Universities, Paris, France. 'INSERM U897, Institut de Santé Publique d'Epidémiologie et de Développement, Laboratoire Santé Travail Environnement, Université de Bordeaux, Bordeaux, France. ${ }^{8}$ Service des Maladies Respiratoires, Hôpital du Haut-Lévèque, Avenue de Magellan, Pessac, France.

Received: 21 May 2015 Accepted: 22 September 2015

\section{Published online: 30 September 2015}

\section{References}

1. Saadeh D, Salameh P, Baldi I, Raherison C. Diet and allergic diseases among population aged 0 to 18 years: myths or reality? Nutrients. 2013; 5(9):3399-423.

2. The International Study of Asthma and Allergies in Childhood (ISAAC) Steering committee. Worldwide variation in the prevalence of symptoms of asthma, allergic rhinoconjunctivitis, and atopic eczema: ISAAC. Lancet. 1998;351(9111):1225-32.

3. Pénard-Morand C, Raherison C, Charpin D, Kopferschmitt C, Lavaud F, Caillaud D, et al. Long-term exposure to close-proximity air pollution and asthma and allergies in urban children. Eur Respir J. 2010;36(1):33-40.

4. Devereux G. The increase in the prevalence of asthma and allergy: food for thought. Nat Rev Immunol. 2006;6(11):869-74.

5. Gupta R, Sheikh A, Strachan DP, Anderson HR. Burden of allergic disease in the UK: secondary analyses of national databases. Clin Exp Allergy. 2004;34(4):520-6.

6. Torres-Borrego J, Molina-Terán AB, Montes-Mendoza C. Prevalence and associated factors of allergic rhinitis and atopic dermatitis in children. Allergol Immunopathol (Madr). 2008;36(2):90-100.

7. Batllés-Garrido J, Torres-Borrego J, Rubí-Ruiz T, Bonillo- Perales A, GonzálezJiménez Y, Momblán De Cabo J, et al. Prevalence and factors linked to atopy in 10-and 11-year-old children in Almería, Spain. Allergol Immunopathol. 2010;38(1):13-9.

8. Björkstén B, Clayton T, Ellwood P, Stewart A, Strachan D, ISAAC Phase III Study Group. Worldwide time trends for symptoms of rhinitis and conjunctivitis: Phase III of the International Study of Asthma and Allergies in Childhood. Pediatr Allergy Immunol. 2008;19(2):110-24.

9. Jenerowicz D, Silny W, Dańczak-Pazdrowska A, Polańska A, OsmolaMańkowska A, Olek-Hrab K. Environmental factors and allergic diseases. Ann Agric Environ Med. 2012;19(3):475-81.

10. Armentia A, Banuelos C, Arranz ML, Del Villar V, Martin-Santos JM, Gil FJ, et al. Early introduction of cereals into children's diets as a risk-factor for grass pollen asthma. Clin Exp Allergy. 2001;31(8):125. 40-5.

11. Hodge L, Salome CM, Peat JK, Haby MM, Xuan W, Woolcock AJ. Consumption of oily fish and childhood asthma risk. Med J Aust. 1996;164(3):137-40.

12. Ding G, Ji R, Bao Y. Risk and protective factors for the development of childhood asthma. Paediatr Respir Rev. 2015;16(2):133-9.

13. La Vecchia C, Decarli A, Pagano R. Vegetable consumption and risk of chronic disease. Epidemiology. 1998;9(2):208-10.

14. Shaheen SO, Sterne JA, Thompson RL, Songhurst CE, Margetts BM, Burney PG. Dietary antioxidants and asthma in adults: population-based case-control study. Am J Respir Crit Care Med. 2001;164:1823-8.

15. Peat JK, Salome CM, Woolcock AJ. Factors associated with bronchial hyperresponsiveness in Australian adults and children. Eur Respir J. 1992;5(8):921-9.

16. von Mutius E, Weiland SK, Fritzsch C, Duhme H, Keil U. Increasing prevalence of hay fever and atopy among children in Leipzig, East Germany. Lancet. 1998;351(9106):862-6.

17. Huang SL, Lin KC, Pan WH. Dietary factors associated with physiciandiagnosed asthma and allergic rhinitis in teenagers: analyses of the first Nutrition and Health Survey in Taiwan. Clin Exp Allergy. 2001;31(12):259-64

18. Huang SL, Pan WH. Dietary fats and asthma in teenagers: analyses of the first Nutrition and Health Survey in Taiwan (NAHSIT). Clin Exp Allergy. 2001;31:1875-80

19. Devereux G, Seaton A. Diet as a risk factor for atopy and asthma. J Allergy Clin Immunol. 2005;115(6):1109-17.
20. Chatzi L, Torrent M, Romieu I, Garcia-Esteban R, Ferrer C, Vioque J, et al. Diet, wheeze, and atopy in school children in Menorca, Spain. Pediatr Allergy Immunol. 2007;18(6):480-5.

21. Tabak C, Wijga AH, de Meer G, Janssen NA, Brunekreef B, Smit HA. Diet and asthma in Dutch school children (ISAAC-2). Thorax. 2006;61(12):1048-53.

22. Nja F, Nystad W, Lodrup Carlsen KC, Hetlevik O, Carlsen KH. Effects of early intake of fruit or vegetables in relation to later asthma and allergic sensitization in school-age children. Acta Paediatr. 2005;94(2):147-54

23. Weiland SK, von Mutius E, Husing A, Asher MI. Intake of trans fatty acids and prevalence of childhood asthma and allergies in Europe. ISAAC Steering Committee Lancet. 1999;353(9169):2040-1.

24. Ellwood P, Asher MI, Björkstén B, Burr M, Pearce N, Robertson CF. Diet and asthma, allergic rhinoconjunctivitis and atopic eczema symptom prevalence: An ecological analysis of the International Study of Asthma and Allergies in Childhood (ISAAC) data. Eur Respir J. 2001;17(3):436-43.

25. Forastiere F, Pistelli R, Sestini P, Fortes C, Renzoni E, Rusconi F, et al. Consumption of fresh fruit rich in vitamin $C$ and wheezing symptoms in children. SIDRIA Collaborative Group, Italy (Italian Studies on Respiratory Disorders in Children and the Environment). Thorax. 2000;55(4):283-8.

26. Nagel G, Weinmayr G, Kleiner A, Garcia-Marcos L, Strachan DP, ISAAC Phase Two Study Group. Effect of diet on asthma and allergic sensitisation in the International Study on Allergies and Asthma in Childhood (ISAAC) Phase Two. Thorax. 2010;65(6):516-22.

27. Naska A, Fouskakis D, Oikonomou E, Almeida MD, Berg MA, Gedrich K, et al. Dietary patterns and their socio-demographic determinants in 10 European countries: data from the DAFNE databank. Eur J Clin Nutr. 2006;60(2):181-90.

28. Asher MI, Keil U, Anderson HR, Beasley R, Crane J, Martinez F, et al. International Study of Asthma and Allergies in Childhood (ISAAC): rationale and methods. Eur Respir J. 1995;8(3):483-91.

29. Annesi-Maesano I, Moreau D, Caillaud D, Lavaud F, Le Moullec Y, Taytard A et al. Residential proximity fine particles related to allergic sensitisation and asthma in primary school children. Respir Med. 2007;101(8):1721-9.

30. Haby MM, Anderson SD, Peat JK, Mellis CM, Toelle BG, Woolcock AJ. An exercise challenge protocol for epidemiological studies of asthma in children: comparison with histamine challenge. Eur Respir J. 1994;7(1):43-9.

31. Caillaud D, Horo K, Baiz N, Banerjee S, Charpin D, Lavaud F, et al. Exerciseinduced bronchospasm related to different phenotypes of rhinitis without asthma in primary schoolchildren: the French Six Cities Study. Clin Exp Allergy. 2014:44(6):858-66.

32. Moeller A, Carlsen KH, Sly PD, Baraldi E, Piacentini G, Pavord I, et al. Monitoring asthma in childhood: lung function, bronchial responsiveness and inflammation. Eur Respir Rev. 2015:24(136):204-15.

33. Gilliland FD, Berhane KT, Li YF, Gauderman WJ, McConnell R, Peters J. Children's lung function and antioxidant vitamin, fruit, juice, and vegetable intake. Am J Epidemiol. 2003;158(6):576-84.

34. Farchi S, Forastiere F, Agabiti N, Corbo G, Pistelli R, Fortes C, et al. Dietary factors associated with wheezing and allergic rhinitis in children. Eur Respir J. 2003;22(5):772-80.

35. Woods RK, Walters EH, Raven JM, Wolfe R, Ireland PD, Thien FC, et al. Food and nutrient intakes and asthma risk in young; adults. Am J Clin Nutr. 2003;78(3):414-21.

36. Tabak C, Smit HA, Rasanen L, Fidanza F, Menotti A, Nissinen A, et al. Dietary factors and pulmonary function: a cross sectional study in middle aged men from three European countries. Thorax. 1999;54(11):1021-6.

37. Miyake Y, Sasaki S, Arakawa M, Tanaka K, Murakami K, Ohya Y. Fatty acid intake and asthma symptoms in Japanese children: The Ryukyus child health study. Allergy. 2008:38(10):1644-50.

38. Almqvist C, Garden F, Xuan W, Mihrshahi S, Leeder SR, Oddy W, et al. Omega-3 and omega- 6 fatty acid exposure from early life does not affect atopy and asthma at age 5 years. J Allergy Clin Immunol. 2007;119(6):1438-44

39. Farrokhi S, Gheybi MK, Movahhed A, Dehdari R, Gooya M, Keshvari S, et al. Prevalence and risk factors of asthma and allergic diseases in primary schoolchildren living in Bushehr, Iran: phase I, III ISAAC protocol. Iran J Allergy Asthma Immunol. 2014;13(5):348-55.

40. Wickens K, Barry D, Friezema A, Rhodius R, Bone N, Purdie G, et al. Fast foodsdare they a risk factor for asthma? Allergy. 2005;60(12):1537-41.

41. Weiland SK, Bjorksten B, Brunekreef B, Cookson WO, von Mutius E, Strachan DP. Phase II of the International Study of Asthma and Allergies in Childhood (ISAAC II): rationale and methods. Eur Respir J. 2004;24(3):406-12. 
42. Debrock C, Menetrey C, Bonavent M, Antonini MT, Preux PM, Bonnaud F, et al. Prevalence of exercise-induced asthma in school children. Rev Epidemiol Sante Publique. 2002;50(6):519-29.

43. Roumelioti $\mathrm{M}$, Leotsinidis $\mathrm{M}$. Relative validity of a semiquantitative food frequency questionnaire designed for schoolchildren in western Greece. Nutr J. 2009;8:8.

44. Vereecken CA, Maes L. A Belgian study on the reliability and relative validity of the health behaviour in school-aged children food-frequency questionnaire. Public Health Nutr. 2003;6(6):581-8.

45. Ahn K, Kim J, Hahm MI, Lee SY, Kim WK, Chae Y, et al. Prevalence of immediate-type food allergy in Korean schoolchildren: a population-based study. Allergy Asthma Proc. 2012;33(6):481-7.

46. Schafer T, Bohler E, Ruhdorfer S, Weigl L, Wessner D, Heinrich J, et al. Epidemiology of food allergy/food intolerance in adults: associations with other manifestations of atopy. Allergy. 2001;56(12):1172-9.

47. Dold S, Wjst M, von Mutius E, Reitmeir P, Stiepel E. Genetic risk for asthma, allergic rhinitis, and atopic dermatitis. Arch Dis Child. 1992;67(8):1018-22.

48. Pearce N, Douwes J, Beasley R. Is allergen exposure the major primary cause of asthma? Thorax. 2000:55(5):424-31.

\section{Submit your next manuscript to BioMed Central and take full advantage of:}

- Convenient online submission

- Thorough peer review

- No space constraints or color figure charges

- Immediate publication on acceptance

- Inclusion in PubMed, CAS, Scopus and Google Scholar

- Research which is freely available for redistribution 